\title{
A FORMAÇÃO DO CAMINHONEIRO VIGILANTE AMBIENTAL EM FOZ DO IGUAÇU (PR)
}

\author{
Daniela Savi ${ }^{1}$ \\ Emerson Ferreira da Silva ${ }^{2}$ \\ Julie Mathilda Semiguem Pavinato ${ }^{3}$ \\ Dirceu Basso ${ }^{4}$
}

Resumo: Este estudo buscou analisar a Educação Ambiental (EA) no contexto do ensino profissional a partir da experiência com o Projeto Caminhoneiro Amigo do Meio Ambiente do SEST/SENAT - Unidade de Foz do Iguaçu/PR. Esse projeto promove a Educação Ambiental e ecológica, preparando os profissionais atendidos para atuarem como mensageiros das boas práticas ambientais para a conservação do meio ambiente. Verificou-se que o projeto analisado constitui uma importante ferramenta para os fins aos quais se propõe, ao disseminar conhecimentos de EA para um público que, em função das especificidades da profissão, tem dificuldades de acesso a esse tipo de formação.

Palavras-chave: Educação Ambiental; Despoluir; Projeto Caminhoneiro Amigo do Meio Ambiente.

1 Universidade Estadual do Oeste do Paraná. E-mail: savi.daniela@hotmail.com

2 Instituto Federal do Paraná. E-mail: emerson.ferreira@ifpr.edu.br

3 Universidade Estadual do Oeste do Paraná. E-mail: julie_pavinato@hotmail.com

4 Universidade da Integração Latino-Americana. E-mail: dirceu.basso@unila.edu.br

Revbea, São Paulo, V. 13, № 3: 96-108, 2018. 


\section{Introdução}

A ampliação do público que acessa a Educação Ambiental (EA) é fundamental para que as boas práticas ambientais, construídas pela sociedade, sejam disseminadas. A utilização de diferentes ambientes educativos (MARCATTO, 2002) adaptados aos diferentes sujeitos que acessam o conhecimento sobre o meio ambiente, contribui para a multiplicação de ações que atuam no sentido da preservação ambiental. Além do poder público, é necessário que a sociedade civil assuma também um papel atuante na disseminação dessas ações, como no caso do programa Despoluir, realizado pela Confederação Nacional do Transporte (CNT) e Serviço Nacional de Aprendizagem do Transporte (SENAT), do qual faz parte o Projeto Caminhoneiro Amigo do Meio Ambiente.

Este relato, contribui para o debate sobre as ações do Projeto Caminhoneiro Amigo do Meio Ambiente para a disseminação de conhecimentos que possam conduzir a práticas de cuidado com 0 meio ambiente. Embora os avanços tecnológicos tenham proporcionado uma série de melhorias em várias áreas, possibilitando a nossa civilização o acesso a uma gigantesca quantidade de objetos que prometem melhorar nossa qualidade de vida, é cada vez mais notório que a natureza não consegue prover os meios necessários à manutenção dos padrões de consumo legitimados por esta sociedade. Neste sentido, é mais que urgente a disseminação de ações que promovam o debate sobre os possíveis caminhos para sairmos da atual crise ambiental. A EA tem um papel fundamental neste debate, ao disseminar conhecimentos para a promoção de práticas que atuem no sentido de colocar em debate os efeitos deletérios que nosso estilo de vida tem provocado.

Desde a revolução industrial o mundo ocidental tem extraído uma quantidade cada vez maior de recursos naturais, devolvendo-os para a natureza em forma de lixo e/ou de contaminantes. Em resposta a este cenário, vários atores têm se mobilizado na busca por alternativas e soluções. Como exemplo simbólico, destacamos o lançamento do livro "Primavera Silenciosa" Silent Spring, de Rachel Carson, em 1962. Resultado de pesquisas iniciadas em 1958, de acordo com PEREIRA (2012), o livro documentou os efeitos deletérios dos pesticidas no ambiente, particularmente em aves. Este episódio inspirou movimentos ambientalistas em diversos países e "[...] é considerado, portanto, o propulsor do despertar da consciência ecológica global e um dos marcos iniciais do que hoje se conhece como Educação Ambiental' (SOUZA, s.d., p. 1).

Diante desses fatos, várias iniciativas e movimentos surgiram, sendo importante destacar: a criação do Conselho para EA, no Reino Unido em 1968; o Clube de Roma, em 1972; a Primeira Conferência Intergovernamental sobre EA, realizada pela UNESCO, em 1977, na cidade de Tbilisi, ex-União Soviética; a Conferência sobre Desenvolvimento e Meio Ambiente, em 1992, na cidade do Rio de Janeiro (Rio-92) e a Conferência Meio Ambiente e Sociedade: 
Educação e Consciência Pública para a Sustentabilidade, organizada pela UNESCO, em Thessaloniki, Grécia, em 1997 (MARCATTO, 2002).

Todos esses eventos contribuíram para a consolidação da EA como importante ferramenta para a construção de uma sociedade sustentável. Atualmente há um grande número de ações para a promoção da EA, principalmente na educação básica, cujo conceito é um dos temas transversais adotados pelo Ministério da Educação nos Parâmetros Curriculares Nacionais. Sendo que seu germe remete à segunda metade da década de 1990, com a aprovação da Lei $n^{\circ} 9.795$, que dispõe sobre a Política Nacional de Educação Ambiental, com a criação da Coordenação-Geral de Educação Ambiental (CGEA) no MEC e da Diretoria de Educação Ambiental (DEA) no MMA (MARCATTO, 2002).

Segundo dados de Veiga (2005), em 2001, o número de escolas que ofereciam EA era de aproximadamente 115.000 , ao passo que, em 2004, este número aumentou para, aproximadamente, 152.000 escolas, apresentando uma taxa de crescimento de $32 \%$ no período. Esses dados são confirmados quando analisados os números da formação continuada em EA dos professores de educação básica: em 2012, foram 8.162, à medida que em 2013, foram 12.813, em 2014, totalizou 15.904 e em 2015, atingiu um total de 17.772. Percebemos que de 2012 a 2015, o número de professores da educação básica capacitados para trabalhar EA cresceu 117, 74\% (INEP, 2016).

Todavia, faz-se necessário destacar também a importância de ampliar esse debate sobre EA para outros espaços, de modo que os sujeitos que não tiveram acesso a esse conhecimento nos bancos escolares também possam engajar-se em ações em direção ao saber ambiental (LEFF, 2009). Assim, a EA é adotada como um instrumento que demonstra que o ser humano é capaz de gerar mudanças significativas ao trilhar caminhos que levam a um mundo socialmente mais justo, igualitário e ecologicamente mais sustentável. Para que isso seja possível, deve-se considerar o lado racional juntamente com o sensível e de valores, a fim de proporcionar experiências mais significativas, que promovam o interesse e o engajamento do indivíduo na defesa do ambiente.

Nesse sentido, objetivou-se no presente trabalho estudar o Projeto Caminhoneiro Amigo do Meio Ambiente, promovido pela Confederação Nacional do Transporte (CNT) e Serviço Nacional de Aprendizagem do Transporte (SENAT).

Entendemos que tal projeto mantém relação com o texto da Conferência Tbilisi, que recomenda que a EA dirija-se "a todos os grupos de idade e categorias profissionais" e não somente àqueles que estão nos bancos escolares, mas ao "público em geral, não-especializado, composto por jovens e adultos cujos comportamentos cotidianos têm uma influência decisiva na preservação e melhoria do meio ambiente" (TBILISI, 1977). 


\section{EA e os diferentes ambientes educativos}

A construção de uma sociedade sustentável só será possível quando os cidadãos se tornarem protagonistas da construção de uma sociedade onde o respeito ao meio ambiente seja internalizado por todos. É nesse contexto que a EA assume um lugar de destaque ao possibilitar a disseminação de práticas que despertem para uma nova racionalidade, onde o encontro de saberes conduza à superação da crise ambiental (LEFF, 2009).

Diferentes autores, mesmo de correntes diferentes, debruçam-se na tentativa de definir a EA. Para Mousinho (2003), EA é o

Processo em que se busca despertar a preocupação individual e coletiva para a questão ambiental, garantindo o acesso à informação em linguagem adequada, contribuindo para o desenvolvimento de uma consciência crítica e estimulando o enfrentamento das questões ambientais e sociais. Desenvolvese num contexto de complexidade, procurando trabalhar não apenas a mudança cultural, mas também a transformação social, assumindo a crise ambiental como uma questão ética e política (MOUSINHO, 2003, p. 367).

Para Mousinho (2003), a EA desperta no indivíduo uma atuação crítica, capaz de superar as relações sociais vigentes, objetivando um patamar societário e rompendo com os padrões dominantes que caracterizam a contemporaneidade.

A EA é também compreendida como "contribuição na construção de uma alternativa civilizatória e societária para a relação sociedade-natureza" (TOZONI-REIS, 2004, p. 12). Segundo Loureiro (2002, p. 69), a Educação Ambiental é

[...] uma práxis educativa e social que tem por finalidade a construção de valores, conceitos, habilidades e atitudes que possibilitem o entendimento da realidade de vida e a atuação lúcida e responsável dos atores sociais individuais e coletivos no ambiente.

Dentro dos conceitos apresentados, a EA é sintetizada como uma práxis educativa e social, que determina a concepção de valores, conceitos, habilidades e atitudes que proporcionem a percepção da realidade de vida e a atuação lúcida e responsável de atores sociais individuais e coletivos no ambiente. "A EA estabelece processos práticos e reflexivos que levem à consolidação de valores que possam ser entendidos e aceitos como favoráveis à sustentabilidade global, à justiça social e à preservação da vida" (LOUREIRO et al., 2003, p. 15-16). 
Em síntese, a Educação Ambiental compreende que o processo educativo é composto por atividades integradas formais, informais e nãoformais, estando fundamentada numa concepção pedagógica norteada por alguns princípios (QUINTAS, 2000 apud LOUREIRO et al., 2003):

- educação como instrumento mediador de interesses e conflitos entre atores sociais que agem no ambiente, usam e se apropriam dos recursos naturais de modo desigual;

- $\quad$ percepção do problema ambiental como questão mediada pelas dimensões econômicas, políticas, simbólicas e ideológicas, que ocorrem em dado contexto e que determinam a compreensão cognitiva do mesmo;

- entendimento crítico e histórico das relações existentes entre educação, sociedade, trabalho e natureza;

- desenvolvimento da capacidade de usar saberes para agir em situações concretas do cotidiano de vida;

- $\quad$ preparação dos sujeitos da ação educativa para que se organizem e intervenham em processos decisórios nos diferentes espaços de participação existentes no Estado brasileiro;

- priorização dos atores sociais em situação de maior vulnerabilidade socioambiental como sujeitos da ação educativa.

Segundo Guimarães (1995), a Educação Ambiental é um processo educativo orientado para a participação de seus atores, educados e educadores na criação de uma maior qualidade de vida. $\mathrm{O}$ autor afirma que a EA vem sendo orientada para a solução de problemas locais, por serem participativos, comunitários, criativos, além de valorizar a ação.

Para Jacobi (2003), a sociedade atual é uma "sociedade de risco", pois a manutenção do estilo de vida moderno demanda uma série de recursos dos quais muitos são extremamente agressivos ao meio ambiente, enquanto outros ainda sequer têm seus efeitos conhecidos a longo prazo, como os organismos geneticamente modificados. Para o autor, essa "sociedade de risco" não é compatível com a sustentabilidade, por isso "a necessidade de se multiplicarem as práticas sociais baseadas no fortalecimento do direito ao acesso à informação e à EA em uma perspectiva integradora" (JACOBI, 2003, p. 192).

O Projeto Caminhoneiro Amigo do Meio Ambiente apropria-se dessa necessidade ao possibilitar aos profissionais atendidos pelo programa o acesso a um ambiente educativo adequado as suas especificidades, em que 0 processo educativo dialoga diretamente com as situações cotidianas desses motoristas. Nessa perspectiva, Paula e Henrique (2016) argumentam que "trabalhar situações reais é imprescindível para que os sujeitos se percebam parte do meio e sintam-se por ele responsáveis, já que o respeito ao meio ambiente se constrói em um fazer e pensar diários" (PAULA; HENRIQUE, 2016, p. 90). 


\section{Materiais e Métodos}

A metodologia adotada inicialmente foi a pesquisa Bibliográfica e Documental em sites e informativos do Programa Despoluir, reunindo referencial teórico para a apresentação do Programa.

A abordagem geral de investigação foi, a priori, com foco no estudo de caso, sendo adotado, durante toda a coleta de dados, o papel de observador participante, constituindo-se a participação do tipo conhecida pelos observados.

A amostragem pesquisada é constituída pelos participantes do curso Caminhoneiro Amigo do Meio Ambiente, promovido pelo Serviço Nacional de Aprendizagem do Transporte (SENAT), unidade Foz do Iguaçu-PR. A estratégia utilizada foi a de afunilamento da amostra, em que se optou por estudar especificamente este grupo de participantes.

Após definir o público-alvo e o local a ser pesquisado, solicitamos a permissão do Serviço Nacional de Aprendizagem do Transporte (SENAT) para realizar a coleta de dados. Posteriormente, foi desenvolvido o protocolo de observação, que se constituiu de um quadro com cabeçalho que descreve todas as informações sobre o grupo observado, constituindo-se, portanto, de observações descritivas e reflexivas. A pesquisa foi realizada no mês de março de 2017.

\section{Resultado e Discussão}

O Projeto Caminhoneiro Amigo do Meio Ambiente faz parte do Programa Ambiental do Transporte - Despoluir, desenvolvido pela Confederação Nacional do Transporte (CNT) em parceria com o Serviço Nacional de Aprendizagem do Transporte (SENAT). O Despoluir foi criado em 2007, com o objetivo de "[...] promover o engajamento de transportadores, caminhoneiros autônomos, taxistas e sociedade em ações de conservação do meio ambiente, como forma de colaborar para a construção de um modelo sustentável de desenvolvimento" (CNT, 2007).

O Despoluir é estruturado em dois grupos de projetos, o primeiro grupo, Projeto Transporte, é voltado para melhorar o desempenho ambiental do setor, e o segundo grupo, Projeto Cidadania para o Meio Ambiente, busca transformar os agentes do setor do transporte em multiplicadores da Educação Ambiental para toda a sociedade (Tabela 1). 
Tabela 1: Estrutura do Programa Ambiental do Transporte - Despoluir

\begin{tabular}{cc}
\hline \multicolumn{2}{c}{$\begin{array}{c}\text { Programa Ambiental do Transporte } \\
\text { Grupo de Projeto Cidadania para o Meio } \\
\text { Ambiente }\end{array}$} \\
$\begin{array}{cc}\text { Projeto I - Redução da Emissão de Poluentes } \\
\text { pelos Veículos }\end{array}$ & $\begin{array}{c}\text { Projeto IV - Taxista Amigo do Meio Ambiente } \\
\text { Projeto II - Incentivo ao Uso de Energia Limpa } \\
\text { pelo Setor Transportador }\end{array}$ \\
$\begin{array}{c}\text { Projeto III - Aprimoramento da Gestão } \\
\text { Ambiental nas Empresas, Garagens e }\end{array}$ & $\begin{array}{c}\text { Projeto VI - Trabalhador em Transporte } \\
\text { Terminais de Transporte }\end{array}$ \\
Amigo do Meio Ambiente \\
\hline
\end{tabular}

Os principais resultados do projeto são apresentados na Tabela 2:

Tabela 2: Principais resultados do Programa Ambiental do Transporte - Despoluir.

\section{Programa Ambiental do Transporte}

\begin{tabular}{|c|c|c|c|}
\hline $\begin{array}{c}\text { Grupo de Projetos } \\
\text { Transporte }\end{array}$ & Principais Resultados & $\begin{array}{c}\text { Grupo de Projeto } \\
\text { Cidadania para o } \\
\text { Meio Ambiente }\end{array}$ & $\begin{array}{l}\text { Principais } \\
\text { Resultados }\end{array}$ \\
\hline $\begin{array}{c}\text { Projeto I - Redução } \\
\text { da Emissão de } \\
\text { Poluentes pelos } \\
\text { Veículos }\end{array}$ & $\begin{array}{c}\text { Mais de } 2 \text { milhões de } \\
\text { avaliações veiculares } \\
\text { ambientais. }\end{array}$ & $\begin{array}{l}\text { Projeto IV - } \\
\text { Taxista Amigo do } \\
\text { Meio Ambiente }\end{array}$ & $\begin{array}{c}\text { Capacitação de } \\
1.291 \\
\text { profissionais. }\end{array}$ \\
\hline $\begin{array}{c}\text { Projeto II - Incentivo } \\
\text { ao Uso de Energia } \\
\text { Limpa pelo Setor } \\
\text { Transportador }\end{array}$ & $\begin{array}{c}\text { Publicações como: A } \\
\text { Adição do Biodiesel e a } \\
\text { Qualidade do Diesel no } \\
\text { Brasil; } \\
\text { Os Impactos da Má } \\
\text { Qualidade do Óleo Diesel } \\
\text { Brasileiro; entre outros. }\end{array}$ & $\begin{array}{c}\text { Projeto V- } \\
\text { Caminhoneiro } \\
\text { Amigo do Meio } \\
\text { Ambiente }\end{array}$ & $\begin{array}{c}\text { Capacitação de } \\
2.204 \\
\text { profissionais. }\end{array}$ \\
\hline $\begin{array}{c}\text { Projeto III - } \\
\text { Aprimoramento da } \\
\text { Gestão Ambiental nas } \\
\text { Empresas, Garagens } \\
\text { e Terminais de } \\
\text { Transporte }\end{array}$ & $\begin{array}{c}\text { Publicações como: } \\
\text { Mudança Climática e o } \\
\text { Transporte Brasileiro rumo } \\
\text { à COP 15; Manual CNT de } \\
\text { Gestão Hídrica - Transporte } \\
\text { Rodoviário Coletivo de } \\
\text { Passageiros; }\end{array}$ & $\begin{array}{l}\text { Projeto VI - } \\
\text { Trabalhador Em } \\
\text { Transporte Amigo } \\
\text { do Meio Ambiente }\end{array}$ & $\begin{array}{c}\text { Capacitação de } \\
9.736 \\
\text { profissionais. }\end{array}$ \\
\hline
\end{tabular}

Fonte: Adaptado pelo autor, com base no Programa Ambiental do Transporte - Despoluir (2017).

Pelo Grupo de Projetos Cidadania para o Meio Ambiente, mais de 13.000 pessoas já foram alcançadas diretamente pelos cursos voltados à EA, além das pessoas que foram atingidas por materiais informativos, como 
cartilhas e folder ${ }^{5}$ distribuídos em todo o território nacional pelo SEST SENAT durante suas campanhas mensais de promoção social.

O Projeto inicialmente promove a capacitação do caminhoneiro por meio de Curso de formação intitulado Caminhoneiro Amigo do Meio Ambiente, promovido pelo SENAT, nas suas 145 unidades distribuídas por todo o país. O Curso tem o objetivo de introduzir o tema ambiental para estes profissionais do setor de transporte, além da contribuição do condutor como multiplicador de práticas que contribuam com a redução dos impactos ao meio ambiente no que diz respeito às principais questões do debate atual: o aquecimento global, a chuva ácida, as diversas fontes de poluição, a questão do lixo e da reciclagem, o combate às queimadas e ao tráfico de animais e madeira. $O$ curso é dividido em quatro unidades; Temas ambientais atuais, Meio Ambiente e Poluição, Responsabilidade Ambiental e $\mathrm{O}$ caminhoneiro amigo do meio ambiente.

A metodologia utilizada na aplicação do Curso são aulas expositivas, Estudo de caso, Debates e Dinâmica de grupo. O Curso possui duração de 8 horas.

Após a capacitação, o caminhoneiro é incentivado a atuar como vigilante para comunicar queimadas próximas às estradas e denunciar crimes ambientais, como poluição de rios, tráfico de animais silvestres, plantas e madeiras. Para isso, existe o serviço "0800 ambiental", em que o caminhoneiro realiza a chamada e faz a notificação/denúncia, que posteriormente é encaminhada para as autoridades competentes pela Confederação Nacional do Transporte (CNT). Estabeleceram-se também parcerias com órgãos ambientais para tornar tais ações mais efetivas.

Cabe ressaltar a existência de vários estudos que visam aprofundar a reflexão em distintas perspectivas sobre as experiências de EA voltada a adultos, destacando-se o realizado por Hiramisis Paiva e Paula em sua tese de doutorado realizada na Universidade Federal do Rio Grande do Norte (UFRN), em 2005. O texto apresenta propostas de assentamentos rurais sustentáveis por meio da qualificação ambiental de seus atores por docentes da UFRN. Outro importante estudo foi desenvolvido por Freitas e Bernardes (2013) e apresentado no XI Congresso Nacional de Educação (EDUCERE), expondo o papel da Educação Ambiental em espaços de educação não formais, como em museus, memoriais, pontos turísticos, meios de comunicação, espaços de lazer e consumo e programas institucionais voltados à comunidade. $O$ estudo conclui que a Educação Ambiental em espaços não formais possui a capacidade de formar cidadãos críticos, que desenvolvam suas ações por meio da participação ativa em prol das melhorias da qualidade ambiental, não se restringindo à dimensão naturalista de ambiente.

\footnotetext{
5 São materiais informativos voltados à conscientização socioambiental dos trabalhadores do transporte e da sociedade em geral, tratando de temas do cotidiano dos transportadores, como queimadas, reciclagem de lixo, manutenção correta e eficaz dos equipamentos entre outros.
}

revista brasileira educação ambiental 
Neste texto, apresentamos um estudo de caso acerca de uma turma do Curso Caminhoneiro Amigo do Meio Ambiente, realizado na unidade SENATFoz do Iguaçu. A escolha desta unidade ocorreu devido a sua localização estratégica no modal rodoviário, por possuir o maior porto seco em movimentação de carga da América Latina, atraindo caminhoneiros de todo o país e da América do Sul.

A turma estudada era composta de 14 alunos, todos do sexo masculino. Segundo pesquisa da CNT, em 2016, 99,8\% dos caminhoneiros do país são do sexo masculino e $0,2 \%$ do sexo feminino. A idade média dos alunos era de 34 anos, provenientes de vários estados do país, como São Paulo, Bahia, Minas Gerais, Rio Grande do Sul, Santa Catarina e Paraná. Quanto à escolaridade, dos 14 participantes, apenas 03 possuíam o ensino médio, 09 possuíam o ensino fundamental e 02 não possuíam alfabetização. Esses dados corroboram com o perfil dos caminhoneiros no Brasil, segundo pesquisa realizada pela CNT, em 2016, em que $1 \%$ dos caminhoneiros não eram alfabetizados, $54,4 \%$ possuíam o ensino fundamental, $41,5 \%$ o ensino médio e 3,2\% o ensino superior.

No que se refere à sistematização do processo, inicialmente ocorreu a divulgação do Projeto Despoluir, pela CNT, criando uma demanda de inscritos ${ }^{6}$ para participar do curso Caminhoneiro Amigo do Meio Ambiente. No segundo momento, acontece o curso, com carga horária de 08 horas, sendo ministrado em um único dia.

O curso é iniciado com uma roda de conversa, procurando identificar o conhecimento prévio dos alunos em temas ambientais. Em seguida, foram introduzidos estudos de caso para embasar a aula expositiva. Os estudos de caso trouxeram relatos impactantes, como a escassez dos recursos naturais, o impacto das queimadas no meio ambiente e a falta de percepção dos problemas ambientais e suas consequências. A aula expositiva foi ministrada com uma linguagem coloquial, utilizando-se de materiais como vídeos e figuras para exemplificar os temas tratados, de modo que os alunos obtivessem compreensão de todos os conceitos adotados.

Posteriormente realizou-se uma dinâmica em que os alunos adquiriram conhecimento de forma lúdica. A dinâmica consistiu-se na formação de grupos, que recebiam casos relacionados ao tema ambiental. Aos alunos cabiam propor soluções para as problemáticas apontadas. Na sequência, realizou-se a apresentação dos casos e soluções propostas por cada grupo e paralelamente efetuou-se uma discussão sobre as soluções adotadas.

6 As inscrições foram gratuitas e realizadas diretamente nas unidades operacionais do SEST SENAT, localizadas em todo território nacional.

Revbea, São Paulo, V. 13, № 3: 96-108, 2018. 
Temos colegas que ainda não se atentaram para o meio ambiente, continuam a jogar lixo nas estradas, bitucas de cigarro e óleo usado/velho. Esse tipo de curso é importante para mudar a forma de pensarem e agirem (PARTICIPANTE XII).

Para finalizar o curso, foi aplicada uma avaliação com questões sobre os conteúdos trabalhados e simulações de como relatar queimadas ou crimes ambientais no "0800 ambiental". Foi realizada, posteriormente, a certificação dos alunos presentes.

Eu gostei do curso, porque agora teremos um número para ligar e denunciar as queimadas na beira da estrada em qualquer lugar do Brasil. Antes, nós até queríamos denunciar, mas não sabíamos para quem ligar, acabávamos ligando para a polícia e relatando as queimadas, agora tudo está centralizado em um único número, vai ser mais prático (PARTICIPANTE III).

Foi utilizada a aula expositiva como metodologia desenvolvida em sala, estimulando um diálogo entre os alunos para que sanassem suas dúvidas ou fizessem levantamentos sobre pontos mais delicados do conteúdo.

Entendemos hoje que cuidar do ambiente é muito mais do que manter a manutenção dos caminhões em dia e usar um diesel que polui menos, é agir como vigilante nas estradas do nosso país, pois o meio ambiente é responsabilidade de todos (PARTICIPANTE VI).

O perfil do grupo estudado possui duas particularidades que merecem destaque: a baixa escolaridade de todos os integrantes, como relatado anteriormente; e a dificuldade de se comunicarem. Para superar essas barreiras, a bagagem de experiência dos indivíduos foi de suma importância, pois contribuiu para desenvolver uma consciência crítica sobre os problemas ambientais uma vez que boa parte dos casos abordados no curso são vistos no dia a dia desses profissionais.

Desta forma, a formação possibilitou a aproximação de um tema aparentemente distante do cotidiano desses profissionais, promovendo a reflexão sobre como a questão ambiental faz parte do dia a dia dos caminhoneiros. Além disso, os participantes foram estimulados a se tornarem sujeitos ativos no combate aos crimes ambientais, tornando-se também vigilantes do meio ambiente. 


\section{Considerações Finais}

O Estado tem um papel indispensável na formulação de políticas públicas para a promoção da EA. Todavia, é necessário que esse papel também seja assumido pelas organizações da sociedade civil, seja protagonista e/ou parceira dos órgãos de Estado na disseminação de práticas que promovam ações em direção a uma sociedade sustentável a exemplo do Projeto Caminhoneiro Amigo do Meio Ambiente.

Os dados levantados neste trabalho nos permitem afirmar que o projeto Caminhoneiro Amigo do Meio Ambiente é uma iniciativa eficiente de fazer com que o acesso a informações sobre cuidados ambientais seja ampliado para um público difícil de ser atingido por esse tipo de capacitação. A forma como o curso é ministrado, com profissionais aptos a utilizarem de linguagem acessível ao perfil desses trabalhadores, constitui um meio facilitador para que a mensagem transmitida no curso seja assimilada pelos participantes. Isso se mostra relevante, sobretudo pela carga horária reduzida do curso, pois dada a extensa jornada de trabalho dessa categoria profissional, seria pouco acessível/aberta uma formação com uma carga horária maior. Nesse sentido, faz-se necessário o máximo aproveitamento do tempo do curso, o que é feito a partir de metodologias adequadas ao perfil dos participantes ao inseri-los no processo educativo (GUIMARÃES, 1995).

Diante da necessidade de ampliação de ações que possam levar a práticas que atuem no sentido de reverter a "sociedade de risco" (JACOBI, 2003) na qual vivemos hoje, é fundamental que informações que promovam mudanças no estilo de vida moderno sejam disseminadas para um número cada vez maior de sujeitos.

A Educação Ambiental (EA) ocorre como um mecanismo para que a sociedade possa organizar-se socialmente, garantindo, assim, o acesso de todos à informação, para que possam atuar no sentido de construir uma sociedade mais sustentável.

\section{Referências}

BRASIL. Instituto Nacional de Estudos e Pesquisas Educacionais Anísio Teixeira. Relatório de monitoramento das metas do PNE: biênio 2014-2016. Brasilia, DF: Inep, 2016.

CLICKFOZ. Porto Seco de Foz do Iguaçu supera marca histórica de liberação de cargas. 2017.2 Disponível em: <http://www.clickfozdoiguacu.com.br/porto-seco-de-foz-do-iguacu-superamarca-historica-de-liberacao-de-cargas/>. Acesso em: 03 de jan. de 2018. CONFEDERAÇÃO NACIONAL DOS TRANSPORTES - CNT. Despoluir Programa Ambiental do Transporte. Disponível em: $<$ http://www.cntdespoluir.org.br/Paginas/Apresentacao.aspx>. Acesso em: 03 de nov. de 2016. 
CONFEDERAÇÃO NACIONAL DOS TRANSPORTES - CNT. Pesquisa CNT de perfil dos caminhoneiros 2016. Brasília: CNT, 2016. Disponível em $<$ http://www.cnt.org.br/Pesquisa/perfil-dos-caminhoneiros>. Acesso em: $18 \mathrm{de}$ dez. de 2017.

DECLARAÇÃO DE TBILISI. Conferência Intergovernamental de EA. Tbilisi, Geórgia: UNESCO, PNUMA, 14 a 26 de outubro de 1977. Disponível em: <http://www.mma.gov.br/port/sdi/ea/deds/index.html>. Acesso em: dez. 2017.

DESPOLUIR. Dez anos de Despoluir. 2017. Disponível em: $<$ http://www.despoluir.org.br/paginas/principais-resultados>. Acesso em: $18 \mathrm{de}$ jan. de 2018.

FREITAS, B.; BERNARDES, M.B.J. Educação Ambiental: ações educativas em espaços não formais. In: XI Congresso Nacional de Educação - EDUCERE, 2013, Curitiba/PR. Anais. Pontifícia Universidade Católica do Paraná, 2013. p. $30.081-30.099$.

GIL, A.C. Como elaborar projetos de pesquisa. 4.ed. São Paulo: Atlas, 2002.

GUIMARAES, M. A dimensão Ambiental na Educação. Campinas: Papirus, 1995.

JACOBI, P. EA, cidadania e sustentabilidade. Cadernos de Pesquisa, n. 118, p. 189-206, 2003.

LEFF, E. Complexidade, racionalidade ambiental e diálogo de saberes. Educação \& realidade, v. 34, n. 3, 2009.

LIMA, M.A.D.S.; ALMEIDA, M.C.P.; LIMA, C.C. (1999). A utilização da observação participante e da entrevista semiestruturada na pesquisa de enfermagem. Revista Gaúcha de Enfermagem, 20, p. 130-142.

LOUREIRO, C.F.B. EA e movimentos sociais na construção da cidadania ecológica e planetária. In: LOUREIRO, C.F.B.; LAYRARGUES, P.P.; CASTRO, R.S. (Orgs.). Educação Ambiental: repensando o espaço da cidadania. São Paulo: Cortez, 2002.

LOUREIRO, C.F.B.; B. AZAZIEL, M; FRANCA, N. EA e gestão participativa em unidades de conservação. Rio de Janeiro: Ibase: Ibama, 2003.

MARCATTO, C. EA: conceitos e princípios. Belo Horizonte: FEAM, 2002. Disponível em <http://www.scribd.com/doc/702363/Educacao-AmbientalConceitosPrincipios >. Acesso em: 28 de out. 2016.

MOUSINHO, P. Glossário. In: TRIGUEIRO, A. (coord.). Meio ambiente no século 21. Rio de Janeiro: Sextante, 2003. p. 337.

PAULA, J.L.; HENRIQUE, A.L.S. EA na Educação Profissional: caminhando em direção à formação humana integral. Revista Eletrônica Científica Ensino Interdisciplinar, v. 2, n. 5, p. 83-92, 2016.

PAULA, H.P. Educação e sustentabilidade: assentamentos Maria da Paz João Câmara/RN. 2005. Tese de Doutorado. Universidade Federal do Rio Grande do Norte. Programa de Pós-Graduação em Educação.

revista brasileira educação ambiental 
PEREIRA, E.M. 50 anos de Primavera Silenciosa. 2012. Disponível em: $<$ http://avozdaprimavera.blogspot.com.br/2012/11/50-anos-de-primaverasilenciosa.html>. Acesso em: nov. de 2016.

QUEIROZ, D.T.; VALL, J.; SOUZA, A.M.A.; VIEIRA, N.F.C. (2007). Observação participante na pesquisa qualitativa: conceitos e aplicações na área da saúde. Revista de Enfermagem da UERJ, 15, p. 276-283.

SEARA FILHO, G. Apontamentos de introdução à EA. Revista Ambiental, ano 1, v. 1, p. 40-44, 1987.

SEST SENAT. Unidades Operacionais do SEST SENAT. Disponível em: http://www.sestsenat.org.br/Paginas/unidades-operacionais-sest-senat. Acesso em: 12 de nov. de 2017.

SORRENTINO, M. et. al. EA como política pública. Educação e Pesquisa, São Paulo, v. 31, n. 2, p. 285-299, 2005.

SOUZA, M.F. EA: como surgiu e a que se destina. Disponível em: file:///C:/Users/Entrar/Downloads/Microsoft Word - EA como surgiu.pdf.

Acesso em: 03 de nov. de 2016.

TOZONI-REIS, M.F.C. EA: natureza, razão e história. Campinas: Autores Associados, 2004.

VEIGA, A. Um retrato da presença da Educação Ambiental no ensino fundamental brasileiro: o percurso de um processo acelerado de expansão. Brasília, DF: Instituto Nacional de Estudos e Pesquisa Educacionais Anísio Teixeira, 2005. 